\title{
International opportunities for undergraduate forestry students at Canadian universities
}

\author{
by John K. Naysmith ${ }^{1}$
}

\section{Introduction}

"... It being our first experience in Africa we had a great deal of work to do in learning about an entirely different society. We spent much of our time learning the culture, history and society of Ghana. However, we were also in Ghana to work. We did physical labour, participated in meetings with government and nongovernment organizations, assisted in data collection, participated in negotiations with village elders and worked extensively on a project to create an identification manual of woody plants and trees in Ghana's savannah region...

"The Ghana-Canada IN CONCERT exchange program gave us a once-in-a-lifetime opportunity to learn about problems facing developing countries. Not only were we able to learn from highly experienced professionals about the ways in which governments and NGOs are dealing with problems of development, but we also saw how the field of forestry, our discipline of study, has an integral role in sustainable development in developing economies.

"We both came back to Canada quite changed. We now realize how much we have and how wealthy a country like Canada is. We also recognize how wealthy in culture and spirit the people of Ghana are. Our work experience in Ghana has had such a strong impact upon both of us that we are now reconsidering our career choices..." (Sheremata and Anthony 1999).

Stimulating intellectual opportunities and not-to-be-imagined real-life experiences are just two ways of describing undergraduate student exchange programs; programs that involve Canadian forestry students working and studying in countries around the world and undergraduate men and women from those countries attending forestry schools in Canada.

The widespread implementation of international roles by Canadian universities appears to have commenced in the late 1960s and was an extension of the more traditional off-campus programs with which Canadian universities had been involved from the late $19^{\text {th }}$ century. Programs that included distance courses such as those undertaken by Queen's University in 1888 and later by the University of Toronto and McGill University. By the early 1900s, several universities had organized extension departments offering credit and non-credit courses and specialized training programs (Shute 1999).

An extraordinary precursor of the move toward internationalization that was underway by the 1970s involved the University of British Columbia's Faculty of Forestry. In 1956, Hungary's Sopron School of Forestry was in need of safe haven

Key words: Canadian forestry schools, undergraduates, international forestry courses, studies and programs, international exchanges and opportunities for forestry undergrads from Canada and abroad

${ }^{1}$ Faculty of Forestry and the Forest Environment, Lakehead University, Thunder Bay, ON. P7B 5E1. E-mail: john.naysmith@lakeheadu.ca and UBC provided it, and an academic home for all of its faculty and students. By 1961 the majority of the Sopron students had completed their degrees and they, along with their faculty remained in British Columbia to work, some of them in the Faculty of Forestry (Anon. 2002).

Internationalization of Canadian universities was significantly advanced when the Canadian International Development

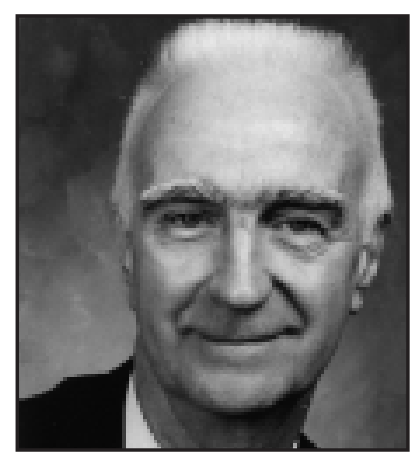

John K. Naysmith Agency (CIDA) established the Educational Institutions Program (EIP) in 1978. Prior to this time, CIDA had involved universities in bilateral projects but with the introduction of EIP a mechanism existed to specifically support institutional linkages involving Canadian universities and colleges. EIP's objectives were to share the expertise and resources of Canadian educational institutions with those of their developing-country counterparts, enable those countries to contribute more effectively to their own development needs, and to expand the knowledge and experience of Canadian institutions (Shute 1999).

In reviewing the current trend of internationalization of Canadian universities, the important role played by Departments and Faculties of Forestry is readily apparent. Hence, the opportunities available to undergraduate forestry students are both diverse in nature and substantial in number.

\section{Undergraduate Forestry Student Exchange Programs \\ University of British Columbia}

UBC Forestry operates a very successful reciprocal exchange program that has evolved substantially over the last six years. It currently has 29 active exchange agreements and 74 students, both incoming and outgoing, participating in exchanges for 2001/02. The Faculty of Forestry, UBC, has one of the highest rates of participation in the exchange program campus- wide. The success has emanated from the faculty's support of international exchanges as an integral part of the undergraduate program.

An effective feature of the UBC Forestry exchange program is the presence of a dedicated three-person team working on international programs for the Faculty to ensure that institutional linkages remain strong and that students have the support they need. International opportunities for UBC forestry undergraduates include the following:

\section{One-year exchanges}

These are the most popular of UBC Forestry's international programs. Students from around the world come to spend a year on the UBC campus and Canadian students have the opportunity to study at a partner institution for a year as well. All of the credits earned overseas are recognized by the student's home 


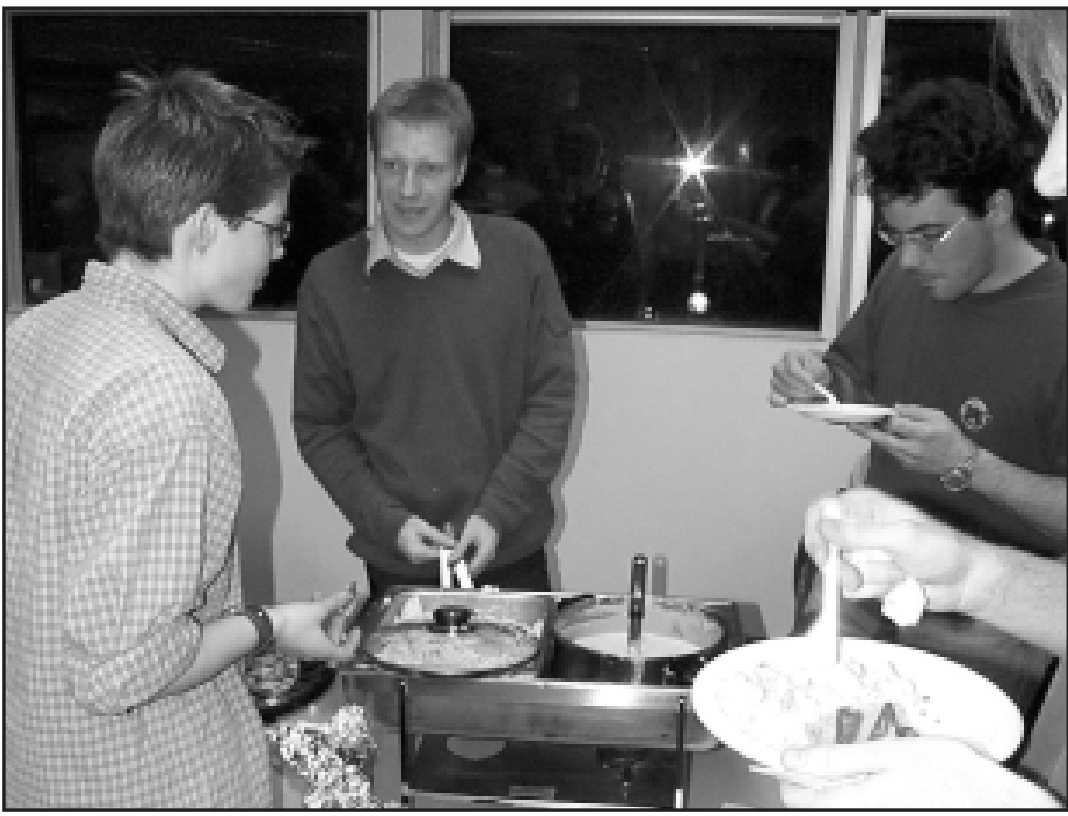

Evan Kelindienst (centre), UBC Forestry student on exchange at the Swedish University of Agricultural Sciences on a student trip to Denmark.

university. Currently there are 58 students participating in the exchange for the 2001/02 academic year.

\section{Student work internships}

The work internship program places eight to twelve students in summer work positions on a yearly basis. To date, students have worked in Sweden, Finland, Germany, Austria, the United Kingdom and China.

\section{Graduate internship program}

Through this program, placements are found for students, recently graduated, through several international youth internship programs that are sponsored by Human Resources Canada. Graduates have had placements in Uruguay, Argentina, Indonesia, Suriname and Mexico.

\section{Intensive study tours}

The International Programs Office coordinates study tours for exchange-partner students, and UBC Forestry students have participated in a number of reciprocal intensive study tours. Recently, tours were organized for students from Norway, Scotland and Germany. Conversely, UBC Forestry students have participated in study tours to Germany, Italy and Austria. Six to ten students participate in these tours on a yearly basis and the number of students interested in this form of international experience is increasing.

\section{Distance education collaborative course}

As part of a Canada-EU Student Mobility grant, which established a consortium of forestry schools in Canada and in Europe, UBC Forestry participated in a distance education course on European forestry. This is an area of great interest to the faculty and they are looking to expand such collaborative efforts in the future.

\section{University of Northern British Columbia}

Currently UNBC has exchange programs with 24 universities in 14 countries, all of which are available to undergraduate forestry students. University-wide, 24 UNBC students are currently participating in these exchange programs and 33 students from those countries are enrolled at UNBC.

The co-operative education program at UNBC provides many opportunities for forestry students including international work opportunities. From the Co-op employer's perspective it appears that the strength of UNBC forestry students is the interdisciplinary nature of the Forestry program. In addition to forestry courses, students take courses in international studies, environmental studies, geography, biology and ethics.

"In what was to be our third year in Prince George at the University of Northern British Columbia, (Heather and Scott) embarked upon an international exchange to study our respective fields of biology and forestry. We chose to attend one of the main campuses of the Swedish University of Agricultural Sciences (SLU) in the northern town of Umeå. It was incredibly good fortune to participate in this exchange, for our experiences there professionally, academically and personally enriched our lives.

"One of the things most amazing about the courses at SLU were the multiple week field trips where our class-work contributed to real ongoing research. (Scott) had two all-inclusive trips paid for by SLU. The first was for a forest meteorology/hydrology course where we set up experiments in a nearby forest. The second trip was to southern Sweden where our class updated the inventory of a 4200-ha estate, developed a 200-year multiple-use management plan and presented our results to the estate manager and a director of SCA, one of Sweden's largest forest companies. (Heather) had a trip into the mountains for her conservation biology class to study wildlife values for grouse and ungulate habitat. These trips were just the beginning of the wonderful opportunities we would experience in Sweden" (Scholefield and Scholefield 2001).

The northern research focus of the University increases students' knowledge of northern resource issues. This northern focus will no doubt become increasingly important as international work opportunities grow, especially in coun- 


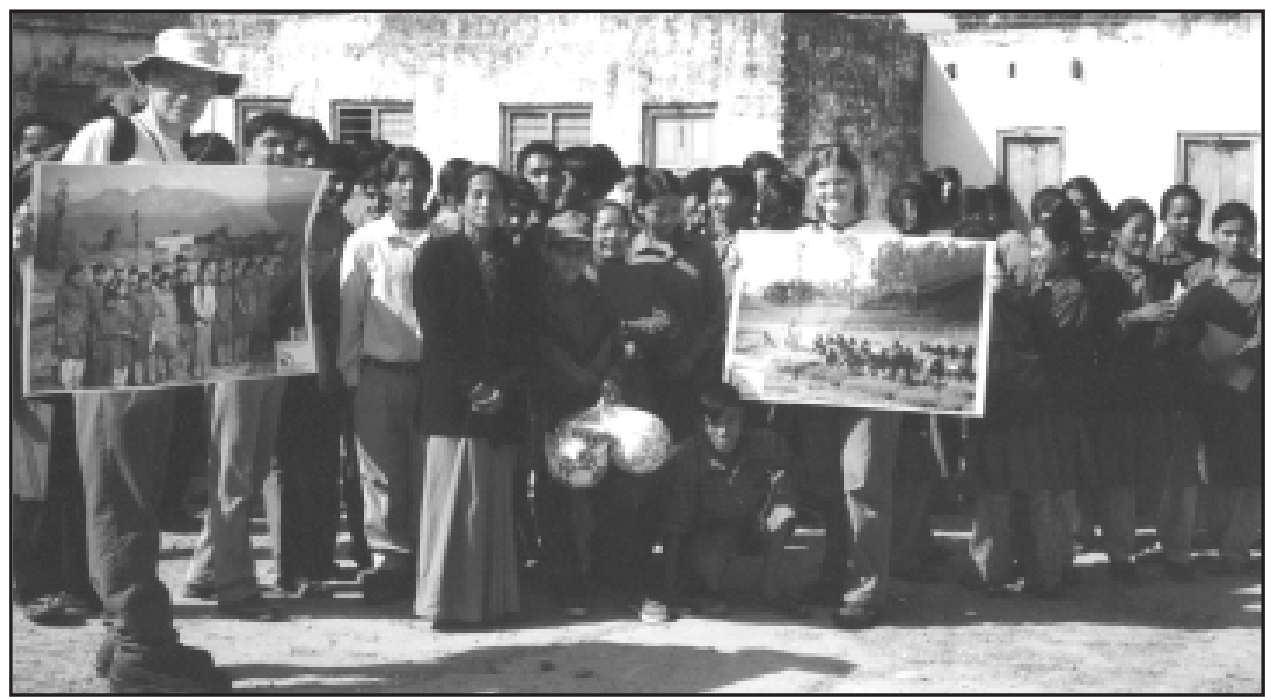

Nick Buda and Jodi Craven, Lakehead University with Headmistress, Mrs. Bella Thapa and students of Mahendra High School at the Project's Conservation Centre, Padam Pokhari, Nepal (Photo credit: J.K. Naysmith).

tries with which UNBC has already firmly established student and faculty exchanges.

\section{University of Alberta}

The international strength of the Forestry program at the University of Alberta is primarily at the graduate level; nevertheless, undergraduate forestry students are provided many opportunities to gain international experience. The President has stated that one of the objectives of the University is to increase the number of undergraduates with international experience before they graduate; specifically, to internationalize ten percent of the graduating class within five years. To this end, the University has formal student-exchange agreements with about 110 universities worldwide.

\section{Lakehead University}

Since 1992 LU's Faculty of Forestry and the Forest Environment and its partner institutions have won four multi-year forestry-related grants worth $\$ 5.2$ million through the Canadian International Development Agency's University Partnerships in Cooperation and Development Program.

The two most recent awards, the $\$ 750000$ Nepal Resource Conservation and Community Outreach Project and the \$2.53 million Ghana-Canada IN CONCERT Program each provide several opportunities for undergraduate student exchanges.

These five-year CIDA-funded Tier 1 and Tier 2 programs enable LU Forestry undergrads to undertake eight-week work terms in Ghana, West Africa or Nepal, Southeast Asia. Conversely, undergraduates from LU's partner universities in Ghana and Nepal come to Canada and learn first-hand about forestry practices and policies through a series of work assignments with consulting firms, government agencies and the forest industry. They participate as well with LU's forestry students in field school and other regular features of academic life.

The experience of two Ghanaian students while at LU prompted them to make the following observations to their home university and their fellow students upon their return to Ghana.

“...Arrangements should be made for our students to gain more practical experience while in school. Apart from the vacation training opportunities and the national park field work, which have been helpful, we suggest that each year students be taken out to various field operations to gain practical experience supplementing what has been taught in class...

"To our classmates we would like to say that although we do not have as much as our Canadian counterparts, the facilities and resources at our disposal are appreciable. What we really need to do is change our perception and attitude toward them. Dedication, commitment and zeal toward work should be our hallmark. We should work towards becoming the best we can in our situation..." (Frempong and Ameyaw 2000).

For their part, LU Forestry exchange students have been involved in a wide array of community-oriented and professional conservation activities in both Nepal and Ghana; activities that include assisting in establishing community tree nurseries and plantations, field mapping of forest areas for subsequent integration into community land use planning, setting up community conservation centres in primary and secondary schools, making presentations in those schools about forestry in Canada, working with university students and faculty to establish permanent sample plots, and developing, with the assistance of practising foresters, tree identification manuals in both countries.

Typical of the comments included in reports made by LU's forestry students upon their return to Canada is the following.

“...Nepal is a fascinating country with a beautiful culture and spectacular scenery. We were both given a unique opportunity to contribute to an international development program, a process made much easier by the friendliness of the Nepalese people. We were given an excellent chance to work with and learn from some amazing people... We both realize the enormous potential even an undergraduate student has to contribute to development projects like these and hope to see ourselves and others involved in them in the future..." (Buda and Craven 2000).

In addition to the CIDA-funded programs, Lakehead University has active articulation agreements with 12 universities around the world. Currently there are 36 exchange students at LU from Australia, Finland, France, Korea, Singapore and Sweden. In recent years, exchange students from Australia, Finland and Germany have taken courses for credit in the Faculty of Forestry and the Forest Environment. 


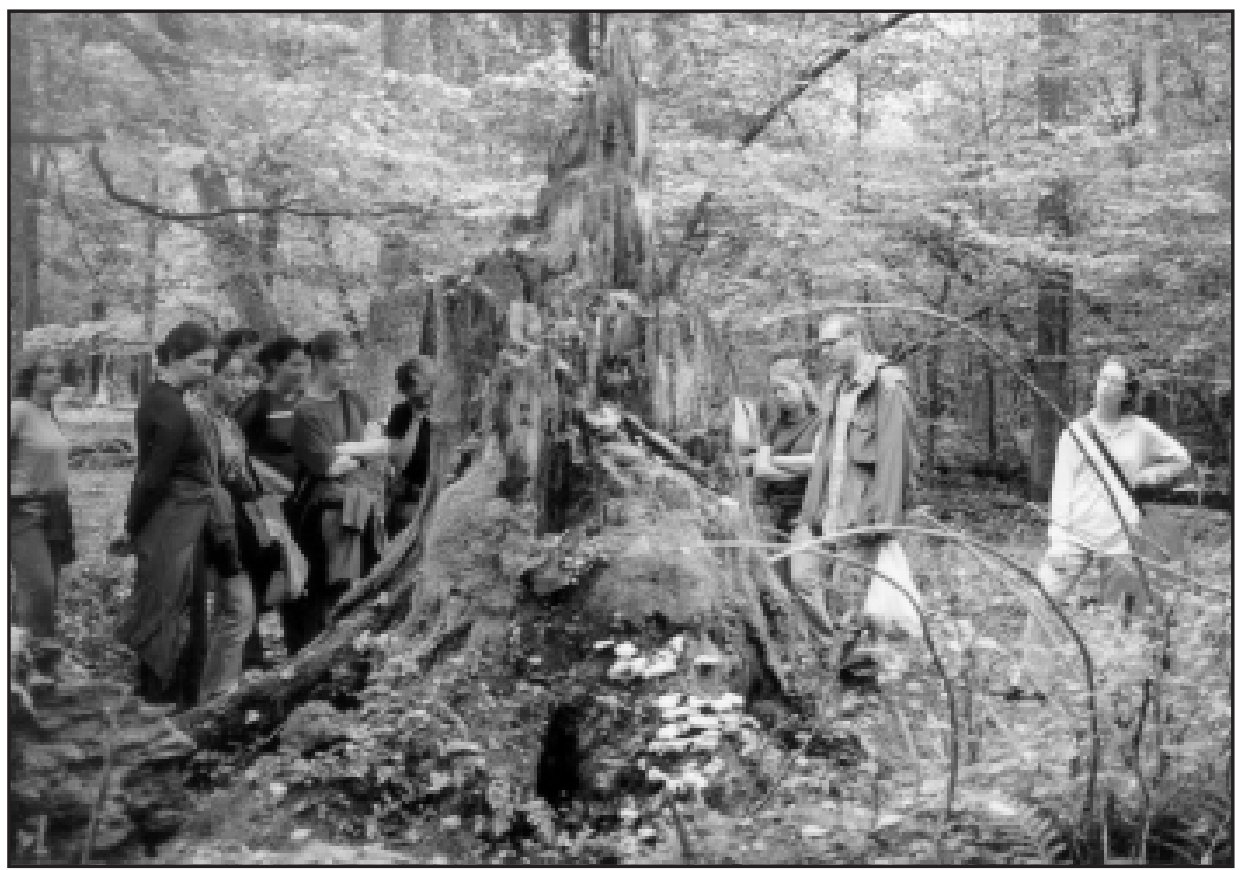

Undergraduate students from the University of Guelph contemplate natural death and destruction in European old-growth forests. Bialowieski National Park, eastern Poland (Photo credit: A.M. Gordon).

\section{University of Guelph}

Student exchange programs at the University of Guelph are numerous and students in the International Development Program participate in many of these. None specifically targets the forest sector, but may involve it. For example as part of the University of Guelph's Semester Abroad Program, eighteen upper-level undergraduate students from various disciplines spent the 1999 Fall Semester attending Jagiellonian University in Krakow, Poland. The course included a series of lectures on Polish forests and forest issues by a faculty member from Guelph's Environmental Biology Department, field trips to research forests throughout Poland and a field project for the students. The trips and project were undertaken with the cooperation of the Faculty of Forestry, Agricultural University of Krakow. Students came away with a broad understanding of current forest issues, many of them relevant to the Canadian forest scene, and an appreciation for the level of commitment to sound forest practices in Poland, a country where the discipline is truly ancient and well-respected.

\section{University of Toronto}

International activity and collaboration is a major focus at the Faculty of Forestry, University of Toronto, strongly encouraged in all the Faculty's programs, and supported through a carefully selected range of active collaboration and exchange agreements.

At present, the Faculty's three undergraduate programs do not include a formal international component, but students are encouraged to consider spending part of their programs abroad, under the umbrella of various Faculty and University exchange agreements. The Faculty currently has exchange agreements with the University of Freiburg (Germany), the Agricultural University of Vienna (Austria), the University of Nuevo Leon (Mexico), the Indian Institute of Forestry Management, Bhopal, the Nanjing Forestry University (China) and the Aristotle University of Thessaloniki (Greece). There are also collective exchange agreements with the Swedish Agricultural University, the
Universities of Helsinki and Joensuu (Finland), the University of Aberdeen and University of Wales, Bangor (United Kingdom), the University of Wageningen (the Netherlands), the University of Gembloux (Belgium) and the University of Padua (Italy) as part of a Canada-Europe Exchange in Higher Education project, in collaboration with the University of British Columbia, the University of New Brunswick and the Université du Québec à Chicoutimi. Under the terms of these agreements a number of students from Toronto have spent periods of various duration abroad, and students from partner universities in Germany, Italy, the Netherlands, Finland and Mexico have spent periods ranging from one term to one year at the University of Toronto. All student exchanges are administered by the Faculty of Forestry and by the University of Toronto International Exchange office.

\section{Université Laval}

The Faculté de Foresterie et de Géomatique has an exchange program comprising two distinct components. One within Canada has been consistently successful in sending annually up to 15 of Laval's best forestry students to other forestry schools in Canada for one year. To date, most of Laval's students have gone to the UBC Forestry program where 42 courses have been identified for which they can receive credit. Conversely, UBC students going to the Laval Forestry program can choose from 37 courses. Laval feels that this program is very important to its students and looks forward to having increased numbers of forestry exchange students from other provinces go to Laval.

International Profil is the other component of the student exchange program in the Faculté de Foresterie et de Géomatique. Currently, the Faculty is developing student exchange protocols with universities in Sweden, France and Costa Rica to enable regular and full-time students to take courses at the host institution while receiving a diploma/degree from their home institution as part of the International Profil d' Université Laval. 


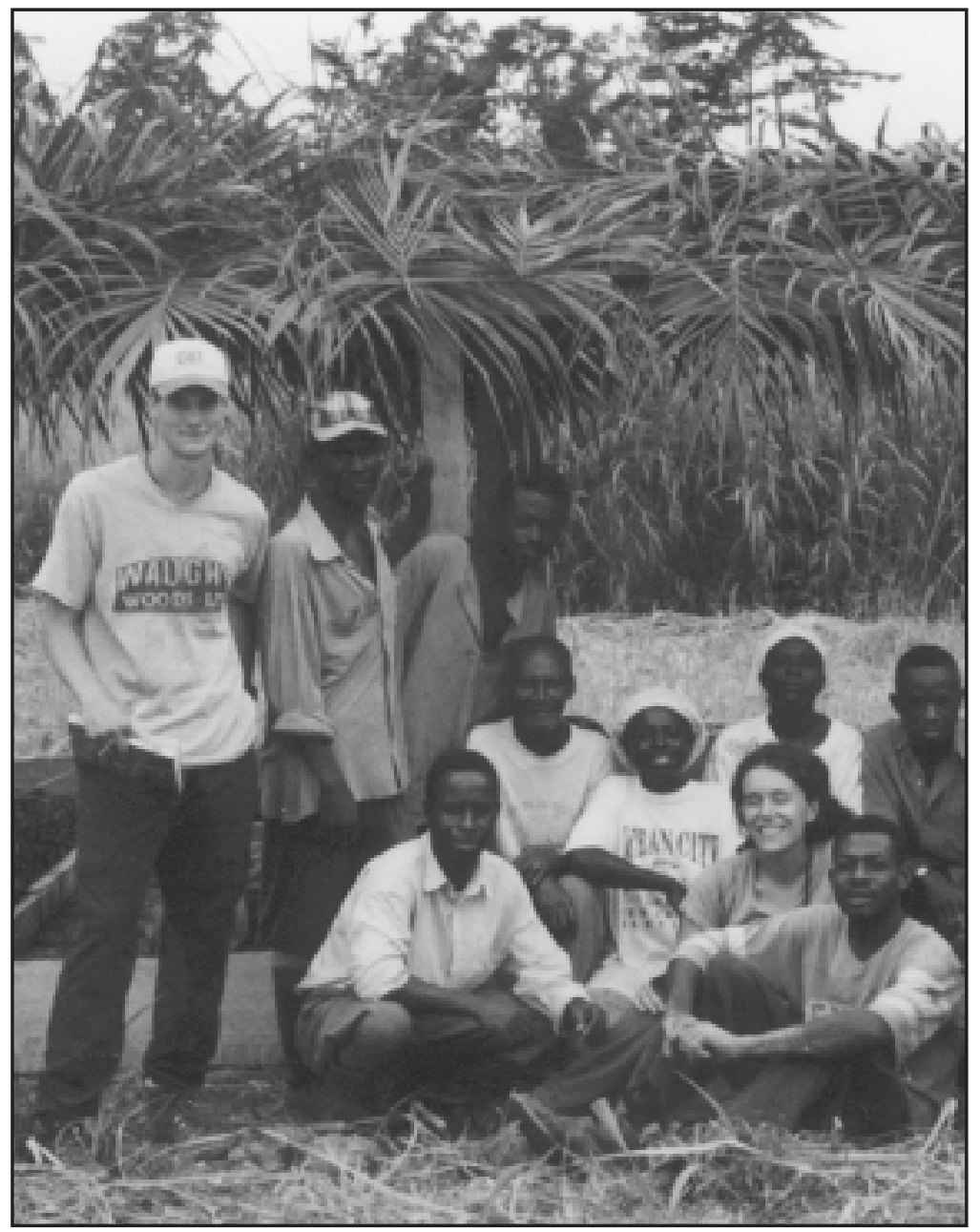

Troy Anthony and Megan Sheremata, Lakehead University, with co-workers in Ghana.

\section{University of New Brunswick}

UNB has exchange agreements with Faculties of Forestry in Austria, Belgium, Chile, Finland, Germany, Italy, the Netherlands, Sweden, UK and USA. Sweden is the most popular destination for UNB forestry students and it was with the Swedish University of Agricultural Science that the current exchange program began in 1995. Opportunities for students to attend universities in Europe are supported by funding from Human Resources Development Canada. In addition to the formal exchange agreements, students are accepted at one another's institutions as "visiting" students. The principal difference is that exchange students pay their home tuition while visiting students pay the tuition of the receiving institution.

Since 1995/96, 22 UNB Forestry students have participated in the exchange program and 30 students from six countries have had the opportunity to share in the academic program of the Faculty of Forestry and Environmental Management at UNB.

\section{Université de Moncton}

The Faculty of Forestry at the Université de Moncton offers several opportunities for its undergraduate students to acquire experience in international forestry. This experience is considered important in preparing forestry students for their future careers. In addition to the benefits that accrue from experience with new concepts, ideas and practices, it also provides the students with opportunities to begin establishing an international network of contacts with forestry professionals and institutions.

Since 1995, the UdeM has had a formal exchange agreement with the Université Catholique de Lowain (UCL) in Belgium. Under the terms of the agreement, UdeM and UCL students can take courses at their respective partner university for one or two semesters. Besides taking courses, all of the students who have participated in the program to date, that is four from Canada and two from Belgium, have travelled throughout the host country and neighbouring regions to learn about their geography and culture.

The main challenge associated with this program is ensuring that courses at UCL are equivalent in content to courses offered at UdeM so that students can obtain the necessary credit bearing in mind the Canadian Forestry Accreditation Board standards.

\section{Undergraduate Courses and Other Interna- tional Initiatives Université de Moncton \\ International courses}

Two international courses are offered in the undergraduate program, one of which is mandatory in the fourth yearForesterie internationale, which addresses several major topics including the ecological, social, economic and political issues related to the management of major forest types around the world. 


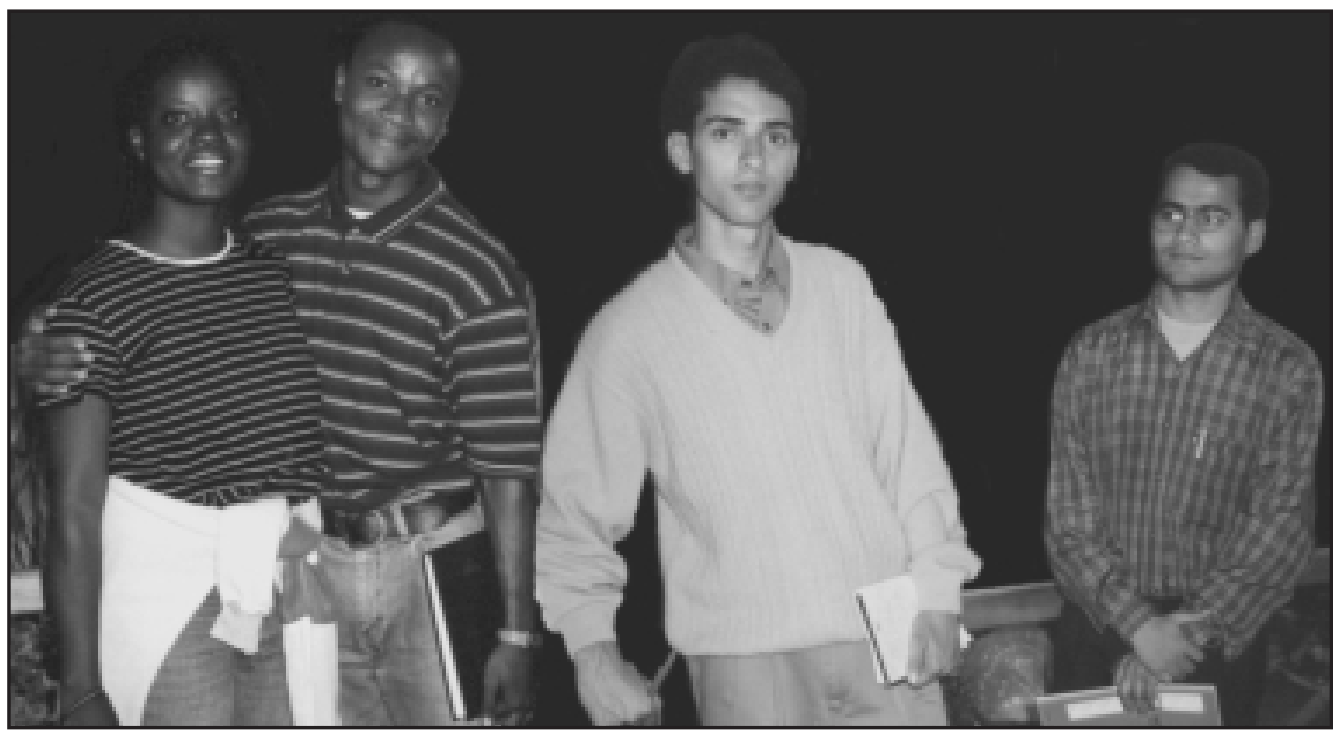

Ghanaian students, Belinda Laryea and Samuel Adjei; and Nepalese students Govinda Paudel and Bidya Jha at Lakehead University's field school (Photo credit: Peggy Smith).

An optional course, Développement et gestion durable des forêts covers international forestry issues mainly at the level of international forest agreements and their impact on forest management throughout the world.

Senior reports on an international forestry topic

A fifth year, six credit, senior report, Projet de fin d'études, is a mandatory degree requirement for all $U d e M$ undergraduate forestry students. Many of the students choose to do their senior reports on international forestry topics. Often, the projects are part of larger projects in which faculty members are involved. In the past, students have produced reports on the following topics: maize culture in Cameroon, village-level agroforestry projects in Cameroon, agricultural and forest policy in Haiti, regional land-use in northern Haiti, the economic contribution of forests in Mexico, the Chiloé Model Forest in Chile, tropical forestry in Peru and the ecological effects of agroforestry in the Peruvian Andes. In all of the projects, students actually visited the countries of interest to gather information for their reports.

\section{Post-degree international professional internships}

Commencing in 2000, students just finishing their forestry degrees at the $U d e M$ have been eligible to participate in a work program funded by Human Resources Development Canada (HRDC) through the Youth Employment Strategy program. The main objective is to facilitate the integration of recent graduates into the Canadian workplace. For UdeM students, this involves a four-month work period in a foreign country in a forestry-related institution.

In 2000, five recent graduates took advantage of this program. One went to Belgium to work for the $U C L$ on a silviculture research project. Two went to Benin to work for the Université Nationale du Bénin (UNB) on agroforestry projects and projects related to non-timber forest products. The other two went to Peru to work for the Associación civil para la investigación y el desarrollo forestal (ADEFOR). One of the two students worked on projects related to forest inventory, forest management and forest operations, and the other on a socio-economic analysis of a rural development project. In 2001, two graduates participated. One went to Belgium to work for the Centre de développement agroforestier de Chimay on forest research projects and the other to Madagascar to work for QIT Madagascar Minerals on a forestry-related Environmental Impact Assessment.

\section{Fraternization with international students}

The UdeM forestry school was established in 1985 and so is relatively young compared to other forestry schools in Canada. Despite this fact, UdeM has been able to attract students from many other countries who have completed all or part of their undergraduate training there. Included are students from Belgium, Cameroon, Congo, El Salvador, France and Haiti. The Faculty also welcomes students doing undergraduate forestry or forestry-related degrees in other countries (mainly France) who come to $U d e M$ to work on various research projects as part of the international work and study degree requirements of their home institutions.

These international students are deemed by the Faculty to be its eyes and ears on what is going on in other parts of the world. Informal fraternization between Canadian and international students in class, on research projects and during social events, contributes considerably to the international forestry and cultural exposure of both groups. Because of this, UdeM hopes to increase the proportion of international students in the near future.

Of the possible opportunities listed above, only the international forestry course is mandatory for the undergraduates. Therefore, the degree to which students are exposed to international forestry issues will vary according to their interests and the choices they make among the various activities while undergraduates.

International activities for undergraduate students often present unusual challenges, including the need for adequate guidance, supervision and personal security. Despite these challenges, UdeM's Faculty of Forestry believes the rewards are great, both personally and professionally and it is committed to ensuring the long-term viability of its international program.

\section{University of New Brunswick}

UNB has two courses related directly to International Forestry/Ecology, each of which has a field trip of up to two weeks as a component of the course. 
The International Forest Studies course focuses on the biophysical, historical, social and economic factors influencing forest management in a region of the world other than Canada. The purpose of the course is to better understand forest management practices within the Canadian context by gaining an understanding of how these factors influence forest management in a region outside of Canada. One of the interesting features of this course is a ten-day to two-week field trip to the region of the world being studied that particular year. Prominent forestry professionals from across Canada accompany the students. A new region is selected each year. The students are charged for the associated travel costs.

A course open to biology and forestry students, International Ecology Field Course, provides students with on-site exposure to and understanding of ecological interactions of soil, climate, plants and animals in a region outside of the Maritimes. This course also includes a ten-day to two-week field trip. UNB also offers a minor (eight term courses) in International Development Studies. This minor is administered by the Faculty of Arts, but is open to Forestry students who wish to put their elective course choices in this area. Courses come from a variety of disciplines including Anthropology, History, Sociology, and Science.

\section{Université Laval}

Three courses with an international focus are offered in the undergraduate program, one of which is mandatory. In addition, there is a wide array of elective courses in allied disciplines available to forestry undergraduates.

Géographie forestière, which is mandatory for students who choose the International Profil referred to earlier, examines the origin and evolution of the world's forests, including the climatic, flora and fauna factors responsible for the establishment of the forests and the role played by human population in their transformation. Also addressed are the distribution of forest types on all continents and the biological and economic details of tree species by region.

Analyse des écosystèmes forestiers tropicaux, one of two international forestry electives, considers a wide array of topics including: climatology of tropical regions, characteristics and classifications of tropical ecosystems, analysis of ecosystem productivity, biochemical cycles, biodiversity, tropical soils, economic aspects of conservation of biodiversity, principles and utilization of remote sensing in examining changes of tropical ecosystems, principles of the ecology of systems and systematic analysis and model utilization as a function of tropical ecosystem analysis.

Rounding out the course offerings is Stage en foresterie internationale, a work placement, or Co-op opportunity in another country. It is described as a practical study of a country's forest resources including forest management practices. An admission exam is taken by prospective candidates and an individual report is written by each student following the completion of the assignment.

Another of Laval's international initiatives that relates to and will have a positive effect upon the forestry undergraduate student exchange initiative is the French language-training program. The training program, which so far applies to Laval's partners in North, Central and South America, is free of charge to all students registering for the autumn and winter semesters, irrespective of their level of French, including those with no
French-language facility. The program comprises five weeks of intensive French courses followed by two weeks dedicated to the French language in the context of a student's particular field, for example forestry.

Upon completion of the two courses, the students are tested to determine what level of continuing French language training would be appropriate for their individual exchange programs. By the winter semester, every student is expected to be full time in his or her own program.

\section{University of Toronto}

At the undergraduate level, the Faculty of Forestry is responsible for three programs, started in September 2000, which are taught in collaboration with the Faculty of Arts and Science. Two are specialist programs in Forest Conservation Sciences (B.Sc.) and Forest Conservation (B.A.), while the third includes major programs in either stream. Although none of the programs includes a formal international component, the Faculty is closely associated with the Cooperative Program in International Development Studies (IDS) at the University of Toronto (Scarborough). This is a five-year undergraduate program that involves a full year internship spent working on international development programs in developing countries with a wide range of international agencies. Several forestry courses are integral components of this program and many students work on forestry-related projects overseas.

\section{University of Guelph}

Guelph's Department of Environmental Biology offers two courses that contain international forestry components. Both courses, one in the second year and one in the fourth year, focus mainly on Canadian forestry and forest ecosystems dynamics; however, students are also exposed to an international perspective on forests and forestry. This view is attained through the inclusion of global subject matter such as the role of forests in the planet's carbon balance, as well as comparisons between the dynamics of boreal, temperate, and tropical forest ecosystems. Specific international examples are also discussed, for example the use of Radiata pine in fast-growing New Zealand plantations and the potential loss of biodiversity in South American tropical rainforests due to forest conversion to pasture land. The topic of agroforestry is introduced and its importance in developing countries is discussed.

\section{Lakehead University}

The undergraduate curriculum in the Faculty of Forestry and the Forest Environment contains two courses that focus wholly on international forestry and related resource issues. Over the past ten years, more than 500 forestry students have taken as part of their elective requirements International Forestry and/or International Resource Conservation.

International Forestry has been designed to assist in developing skills in forest policy analysis as it applies to specific countries or regions around the world and in evaluating international and national forestry and conservation programs and practices. Students are expected to gain an understanding of some of the underlying factors that influence forest land use beyond North America as well as some of the current forest practices and issues in both temperate and tropical regions.

Case studies based on first-hand experience of the instructor and guest speakers in several regions of the world as well 
as knowledge derived and experience gained from LU Forestry's CIDA-funded projects in Africa and Asia provide the core material for the course.

International Resource Conservation is an elective or core course depending upon the undergraduate forestry program of the student. Students taking this course frequently do so in sequence with the International Forestry course.

This course provides students with the opportunity to become informed about and discuss, in a seminar setting, issues surrounding the conservation (wise use) of natural resources in an international context. The course examines the underlying factors that influence resource development around the world with respect to forests, water and land, and how society can identify and deal more effectively with issues related to such development. In examining global issues in this way the student is expected to further develop his or her skills in policy and program analysis, and in evaluating current initiatives that have been designed to address such issues.

Whereas the International Forestry and International Resource Conservation courses are devoted wholly to international topics and draw upon current issues and initiatives in countries on every continent, there is another group of courses that have an international component and contribute significantly to the internationalization of LU's Forestry program.

One such course, an elective, is Remote Sensing Applications in Forestry. Before taking this course students have already had two mandatory courses, namely Photogrammetry and Remote Sensing and Introductory GIS, both of which use actual cases such as national mapping programs in Sweden, Finland, the Congo, Vietnam, Ghana and Nepal or a time series of "greeness" (every ten days over a ten-year period) in subSahara countries is demonstrated and discussed as a tool for famine forecasting.

In the Remote Sensing Applications elective, new trends in vegetation monitoring are examined and students conduct multi-temporal analysis to quantify the areal extent of brush fire and conversion of forests to agriculture in Ghana as well as monsoon-generated erosion in Nepal. Students also generate three-dimensional landscape scenes with the aid of Nepal Survey Department map sheets and integrate Ghanaian land cover data with actual Ghana Survey Department GIS data. Students design a training module for classification accuracy in either a Nepalese or Ghanaian situation.

Depending upon which undergraduate program they are in students must write a thesis report or complete a senior project. The students who have participated in the CIDA-funded workexchange projects frequently undertake those final-year assignments using data and information gathered while in Ghana or Nepal. Some of the topics include "Medicinal Plants and Their Management in Ghana," "Agroforestry in Tropical Regions: Principles and Practices," "Community Forestry with Specific Reference to Nepal," "Environmental Education Manual for a Nepalese Primary School."

\section{University of Alberta}

Undergraduate Forestry students have available to them a number of courses with some international content. Examples of such courses include the following: Natural Resource Economics, Agricultural Policies, Social Factors in Forest Management, Woody Plants, Advanced Dendrology, Environmental Conservation Field Studies, and some wildlife courses.
Independent Studies courses are also used to explore topics with an international focus. Each year, U of A's Forestry program has one or two international students in its graduating class. It should be noted, however, that most of the formal international activity in U of A's Forestry Department is developed through the Graduate Program.

\section{University of Northern British Columbia}

UNBC's forestry undergraduate curriculum contains at least six courses that address international issues. For example Global Resources provides an examination of the interaction between global economic and environmental resources and includes discussions on international topics regarding resources as a major component.

Integrated Resource Management is an introductory course in the principles of management of forest resources including fisheries, recreation, range and wildlife. It includes some international content such as comparison of IRM approaches in other regions of the world to those in B.C.

Environmental Impact Assessment is an analysis of environmental impact statements, their legal framework and methods of environment assessment. It includes international content with regard to legislation and international organizations and processes that influence water and air quality.

Forest Economics addresses contemporary issues in the allocation of natural resources. It has a large international component with regard to, for example, international markets, softwood lumber agreements with the US, trade tariffs and environmental group boycotts.

Society, Policy and Administration is cross-listed with Resource Politics and focuses on B.C. and Canada but does include some international topics with respect to how natural resources and the environment interact with contemporary political systems and social conflict.

First Nations' Approaches to Resource Management and Environmental and Professional Ethics both involve discussion on an international scale as well as in the B.C. and Canadian context. Other courses, including Forest Health, Forest Products, and Watershed Management, have some international content because of inter-regional and global influences.

\section{University of British Columbia}

UBC Forestry has an international forestry option in its forest management and forest sciences programs. Students who undertake this option must select a region of specialization such as the Americas, Asia or Europe. They must study a language, take region-specific electives and take part in an international work internship or exchange approved by the faculty.

There are other courses available to all undergraduate students, including International Forestry and Agroforestry. The first deals with the socio-economic, biological and technological aspects of forestry within an international context, both in the developed and the developing world. The latter concentrates on the integration of farms and forests, including tropical agroforestry systems, non-timber forest products and forest farming.

\section{Conclusion}

Are there international opportunities for undergraduate forestry students at Canadian universities? Indeed there are, and they are writ large. Each of the nine undergraduate programs 
reviewed for this article benefits significantly from the fact that the nine universities involved have made internationalization of their campuses an item of high priority. Also, within each Forestry Faculty or Department there is a cadre of faculty and staff with not only professional experience but also a real interest in international forestry issues and a desire to share both with their students. Finally, and clearly no shortage exists here, an exuberant and growing number of undergraduate students are interested in gaining an international perspective on forestry. These students are keen to broaden their horizons and increase their knowledge of international issues through course material supplemented in many cases by visiting, studying or working abroad as part of their academic program.

The world continues to grow smaller in that we are more aware of events occurring in one region having a direct impact upon other regions. One outcome of the kind of internationalization occurring in Canadian Forestry Schools might be that nations would begin to replace contentious agendas with collaborative processes. If that were so we should mark it down as a global dividend of some consequence.

\section{Acknowledgements}

An article of this nature would never see the light of day were it not for splendid cooperation and substantial contribution from a large number of people. To each of them, I express my gratitude and say thank you. At the universities of: Alberta-
Ross Wein; British Columbia-Sandra Schinnerl; GuelphAndy Gordon, Rick Gray and Naresh Thevathasan; Lakehead-Ulf Runesson; Laval_-Michel Beaudoin; MonctonJean-Marie Binot, Susan Dupuis and Roger Roy; New Brunswick-Dave Daugharty; Northern British ColumbiaCarolyn Russell; Toronto-Rorke Bryan.

\section{References}

Anonymous. 2002. The Sopron foresters. Trek, the Magazine of the University of British Columbia. Winter 2002: 28.

Buda, N. and J. Craven. 2000. Undergraduate student workexchange report, Lakehead University and Nepal. 14 p. (Mimeographed). Frempong, K. and J. Ameyaw. 2000. Undergraduate student work-exchange report, Kwame Nkrumah University of Science and Technology, Ghana - Canada. 8 p. (Mimeographed).

Scholefield, S. and H. Scholefield. 2001. Undergraduate studentexchange report, University of Northern British Columbia and Sweden. 7 p. (Mimeographed).

Sheremata, M. and T. Anthony. 1999. Undergraduate student work-exchange report, Lakehead University and Ghana. 14 p. (Mimeographed).

Shute, J. 1999. From here to there and back again: international outreach in the Canadian university. In S.L. Bond and J.P. Lemasson (eds.). A New World of Knowledge, Canadian Universities and Globalization. pp. 21-43. International Development Research Centre. Ottawa. $294 \mathrm{p}$. 